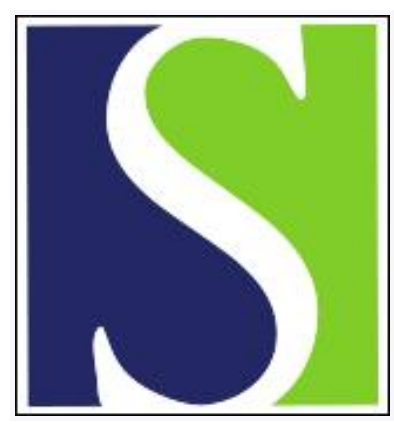

Scand J Work Environ Health 1995;21(4):259-264

https://doi.org/10.5271/sjweh.35

Issue date: Aug 1995

Occupational and environmental mesotheliomas due to crocidolite mining activities in Wittenoom, Western Australia by Rogers A, Nevill M

Key terms: asbestos; environmental contamination; exposure; risk calculations

This article in PubMed: www.ncbi.nlm.nih.gov/pubmed/8552999

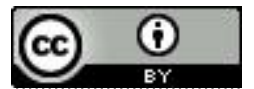




\title{
Occupational and environmental mesotheliomas due to crocidolite mining activities in Wittenoom, Western Australia
}

by Alan Rogers, Msc, ${ }^{\top}$ Mark Nevill, Bsc (Hons) ${ }^{2}$

\begin{abstract}
Rogers A, Nevill M. Occupational and environmental mesotheliomas due to crocidolite mining activities in Wittenoom, Western Australia. Scand J Work Environ Health 1995:21:259-64.

Objectives The aim of the study was to review existing cases, calculate rates, and predict future numbers of occupational and environmental mesotheliomas from Wittenoom.

Methods On the basis of information contained in occupational and environmental histories, Wittenoom cases were extracted from national records collected since 1979. Occupational and residential population estimates were obtained from company and government records. The proportional latency method was used to predict the numbers of mesotheliomas prior to and after the data collection phase. Airborne fiber monitoring was used to calculate risk due to current levels of contamination in the mine and town environments.

Results During 1979-1994, Wittenoom cases $(N=176)$ comprised approximately $6 \%$ of the mesothelioma cases recorded in Australia. Of these 122 were employed directly in the mining and milling activities, another 18 were involved in the transport of raw fiber or tailings, and 34 were town residents or visitors. Due to past exposures, additional occupational $(\mathrm{N}=301)$ and environmental $(\mathrm{N}=83)$ cases can be expected. Dependent on residential time, existing levels of contamination may result in a risk of between $<1$ to 57 per million of the population.

Conclusions Latency effects will result in considerable numbers of mesotheliomas appearing over the next $10-20$ years in Wittenoom. The cessation of mining activities and major clean up of the town will result in reduced mesothelioma cases.
\end{abstract}

Key terms asbestos, environmental contamination, exposure, risk calculations.

Crocidolite mining was carried out in the isolated Wittenoom area of northwest Australia in three separate mining stages and locations from 1937 to 1966 . Initial operations were relatively small, producing a total of $300 \mathrm{t}$ of fiber by 1946. Further development of a mine and mill in the Wittenoom Gorge ran until 1954 with about $20000 \mathrm{t}$ of fiber and $600000 \mathrm{t}$ of waste. The colonial mine and mill was developed from 1953 to 1966 , producing some $130000 \mathrm{t}$ of fiber and about 2.6 million tons of waste (1). Raw fiber was transported by road to Point Samson some $400 \mathrm{~km}$ away; thereafter it was shipped to Fremantle for local consumption or export.

The health outcome of the 6500 miners and millers has been the subject of a series of studies. Surveys conducted by the Department of Public Health indicated that by 1955 considerable asbestosis was present among the work force, and the first case of mesothelioma was observed in 1960 (2). Epidemiologic studies indicated that by 1986 some 94 cases of mesothelioma, 141 lung cancers, and 356 successful compensation claims for asbestosis had been detected among these workers $(3,4)$.

In addition some 4200 residents not directly associated with mining activities lived in the adjacent area. After 1947, most of them were located in the town $8 \mathrm{~km}$ away, while senior staff and their families were housed within $1 \mathrm{~km}$ of the mine and mill. These living areas were subject to considerable exposure, in addition to dust emanating from the mine and mill site, over 3 million tons of tailings were stacked throughout the mining area or used in developing the mine and town infrastructure. It has been estimated that these tailings contained some $64500 \mathrm{t}$ of unclaimed crocidolite fiber, the majority of which is still located adjacent to the mining area (5).

As with many mining operations, contaminated tailings were used extensively by the mine for fill in general and for residential construction, as well as by the local

1 Occupational Hygiene Unit, Worksafe, NSW, Australia.

2 Member Legislative Council, Perth, Western Australia.

Reprint requests to: Mr Alan Rogers, Occupational Hygiene Unit, Worksafe Australia, PO Box 58, Sydney NSW 2001, Australia. 
authority in providing amenities such as road works, car parks, school playgrounds, a race course, a golf course, and a football field. Residents also used the tailings in driveways and gardens and as covering for the ubiquitous red dust in this arid area. With the close of the mine in 1966 the use of tailings was reduced considerably, although it continued well into the 1970s. Concerted efforts by the remaining townspeople and local authorities have removed the majority of surface residues from the township although it is still possible to locate small pockets of fibers in the surrounding soil. The mine site and its surroundings remain heavily contaminated.

Since the early days of the mines, the health status of the nonmining population has been of considerable concern, as indicated in several government reports that summarize medical surveys and air monitoring programs conducted in and around the townships $(6,7)$. Although mining by the Australian Blue Asbestos company ceased some 28 years ago, the town of Wittenoom still exists and is inhabited by approximately 50 permanent residents, some of whom were employed in the original mining operation. Wittenoom has developed as a center for tourism in the nearby Karijini National Park (8) with up to 40000 visitors per year. Public concern has continued as to the risk associated with the residual crocidolite fiber in the area and the first quantitative risk estimates were addressed by us as part of a government inquiry in 1992 (9). This study reports the risks calculated in 1992 with updated observed mesothelioma numbers to June 1994.

\section{Subjects and methods}

Mesothelioma cases associated with Wittenoom ( $N=144$ ) were extracted from the 2398 case records of the Australian Mesothelioma Surveillance Program and Register for the period January 1979 to May 1992 (10, 11). Detailed occupational and environmental histories had been collected by trained interviewers for all cases up until December 1985; since then less stringent exposure information has been obtained. For persons who had been employed at Wittenoom, good information was found in terms of job description and period of employment, and this information was validated against data held in State cancer and compensation registers. Residential status was checked through discussion with existing long-term residents and through cancer registers. Visitor information was not checkable. According to information obtained from recorded occupational and environmental histories each person with mesothelioma was classified as either a mine and mill worker, a person holding other occupation and working directly with crocidolite fiber or tailings, and a nonmining resident or visitor to the area. Another group of 32 Wittenoom cases were extracted from the additional 628 records for the period June 1992 to June 1994, but they were analyzed separately since the occupational and residential status had not been validated to the same degree as had been for the previous group.

Latency was determined for each Wittenoom case, and thereafter the cases were then pooled into five-year periods. A cumulative distribution of the lag period since first asbestos exposure was prepared for all occupations recorded for Australian mesothelioma cases during 1979-1985 (10). The total number of cases and also those for the periods pre-1979 and post-1992 were calculated according to simple proportions derived from the entire Australian latency distribution curve (12) and then scaled up to take into account the observed cases with unknown dates of contact (effectively assuming that these cases had the same distribution of exposure dates as those with known dates). The $95 \%$ confidence intervals $(95 \% \mathrm{CI})$ for these extra cases were calculated using the method of Dobson et al (13).

Population estimates were obtained from government records, census data and school records, as well as from some of the data collated by Hansen et al (14) at various times in the history of the township for residents and visitors not employed directly in the mining and milling operation.

Estimates of the current airborne fiber concentrations in the area were based on monitoring carried out by us in 1992 using the membrane filter method and analytical transmission electron microscopy analysis. Although fibers less than $1 \mu \mathrm{m}$ in length and $0.02 \mu \mathrm{m}$ in diameter were detected in the analysis, only those light microscopy equivalent fiber sizes that were identified as crocidolite, had diameters greater than $0.2 \mu \mathrm{m}$, and conformed with standard membrane filter counting rules were used in the risk calculations. Additional data were available from eight separate environmental air sampling programs using membrane filter methods and phase contrast microscopy conducted between 1966 and 1990 (9). Risk estimates based on airborne crocidolite exposures were calculated according the models of de Klerk et al (4) and Berry (15). Statistics for calculating the nonasbestos risks for residents and tourists were obtained from official government records for the area.

\section{Results}

Past contact with crocidolite at Wittenoom accounts for some $6 \%$ of the mesotheliomas observed in Australia. The data presented in table 1 have been sorted according to the different periods of mining activity. Most of the cases $(72 \%)$ are the result of direct occupational expo- 
Table 1. Wittenoom mesothelioma cases (January 1979-June 1994).

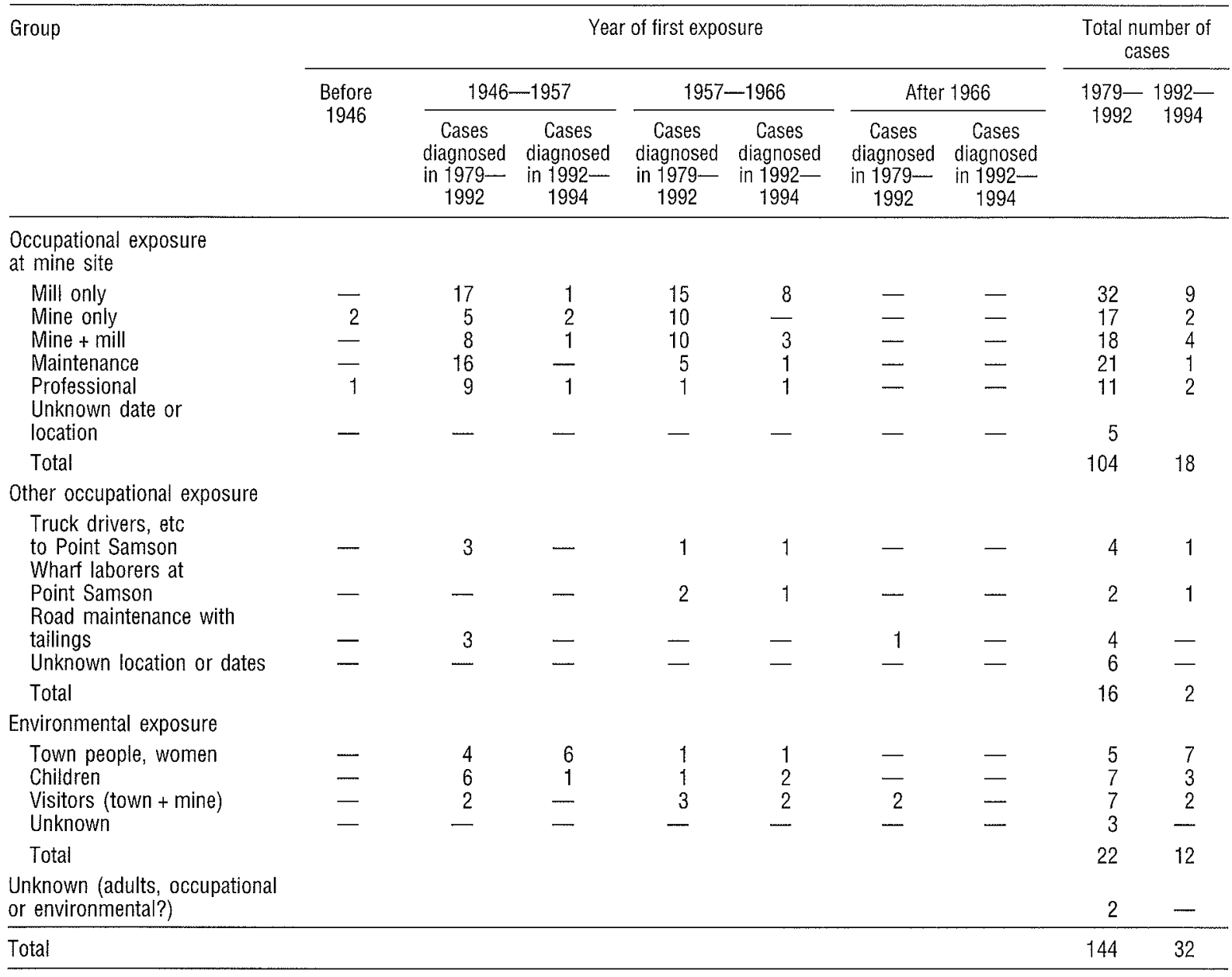

sure at the various mines and mills. Other occupational mesotheliomas $(11 \%)$ were found in workers involved in the handling and transportation of raw fiber or the use of tailings in road construction. Mesotheliomas were found in nonmine employees, such as those employed in service industries in the town or who visited the mine and mill for short periods of time as part of their business $(5 \%)$. Environmental mesotheliomas were found in nonmine employees such as women and children, and also in visitors to the township (10\%).

Thirty-two additional cases were notified in the period June 1992-June 1994. They were analyzed separately since it was not possible to validate the occupational or environmental data to the same degree as for the 1979 - 1992 cases. Of these new cases, 56\% involved persons directly employed in the mine or mill. There was an increase in the proportion of persons involved in operating the colonial mine and mill (1957-1966), where greater numbers were employed, production was higher, and there was a subsequent increase in dust exposure. In addition the latency period of $30-40$ years became more relevant for this mine.
The latency distribution of Australian cases from mixed industries was used as a basis for predicting the total expected mesotheliomas for Wittenoom (12). With the use of the proportion of cases observed in each latency period it was calculated that the total number of mesothelioma cases will be 580 (table 2). According to population estimates, it can be calculated that $1.1 \%$ of the persons who were child residents and $1.9 \%$ of the adult female residents of Wittenoom will die or have died of mesothelioma. This figure compares with $6.0 \%$ of the work force employed at the mine and mill. The latency effects from the time of first exposure for both occupational and environmental mesotheliomas are presented in figure 1.

The observed mortality rate for women and children would appear disproportionately high in comparison with that for persons employed at the mine and mill who were exposed to very high levels of fibers. These higher than expected rates are probably due to a combination of factors, including longer residency in Wittenoom (14) with its subsequent increase in cumulative exposure. Other factors, such as secondary sources of exposure 
Table 2. Estimates of Wittenoom occupational and environmental mesotheliomas derived from scaled proportional latency calculations. ( $95 \% \mathrm{Cl}=95 \%$ confidence interval)

\begin{tabular}{|c|c|c|c|c|c|c|c|c|}
\hline \multirow[t]{2}{*}{ Group } & \multicolumn{2}{|c|}{$\begin{array}{c}\text { Pre-1979 } \\
\text { cases }\end{array}$} & \multirow{2}{*}{$\begin{array}{c}1979-1992 \\
\text { cases }\end{array}$} & \multicolumn{2}{|c|}{$\begin{array}{l}\text { Post-1979 } \\
\text { cases }\end{array}$} & \multicolumn{2}{|c|}{$\begin{array}{l}\text { Total } \\
\text { cases }\end{array}$} & \multirow[t]{2}{*}{$\begin{array}{l}\text { Estimated } \\
\text { population }\end{array}$} \\
\hline & $\begin{array}{l}\text { Estimated } \\
\text { number }\end{array}$ & $95 \% \mathrm{Cl}$ & & $\begin{array}{l}\text { Estimated } \\
\text { number }\end{array}$ & $95 \% \mathrm{Cl}$ & $\begin{array}{l}\text { Estimated } \\
\text { number }\end{array}$ & $95 \% \mathrm{Cl}$ & \\
\hline \multicolumn{9}{|l|}{$\begin{array}{l}\text { Other occupation, worked } \\
\text { with fiber or tailings }\end{array}$} \\
\hline $\begin{array}{l}\text { Truck drivers } \\
\text { to Point Samson } \\
\text { Wharf laborers at }\end{array}$ & 3 & $0.3-6$ & 6 & 19 & $3-52$ & 28 & $10-63$ & - \\
\hline $\begin{array}{l}\text { Point Samson } \\
\text { Road maintenance with } \\
\text { tailings }\end{array}$ & 0 & $0.0-1$ & 4 & 18 & $2-65$ & 22 & $5-69$ & - \\
\hline Total & 6 & $2-10$ & 16 & 52 & $20-103$ & 74 & $40-126$ & - \\
\hline \multicolumn{9}{|l|}{ Environmental exposure } \\
\hline $\begin{array}{l}\text { Town people, women } \\
\text { Children } \\
\text { Visitors (town + mine) }\end{array}$ & $\begin{array}{l}2 \\
3 \\
1\end{array}$ & $\begin{array}{r}0.4-5 \\
1-7 \\
0.1-4\end{array}$ & $\begin{array}{l}6 \\
8 \\
8\end{array}$ & $\begin{array}{l}15 \\
15 \\
54\end{array}$ & $\begin{array}{c}3-39 \\
5-31 \\
14-123\end{array}$ & $\begin{array}{l}23 \\
26 \\
63\end{array}$ & $\begin{array}{l}10-48 \\
15-46 \\
24-133\end{array}$ & $\begin{array}{c}1178^{\mathrm{b}} \\
2450^{\mathrm{b}} \\
-\end{array}$ \\
\hline Total & 6 & $4-11$ & 22 & 84 & $37-148$ & 112 & $65-178$ & - \\
\hline $\begin{array}{l}\text { Unknown (occupational or } \\
\text { environmental?) }\end{array}$ & - & - & 2 & - & - & 2 & - & - \\
\hline Total & 51 & $40-63$ & 144 & 385 & $303-476$ & 580 & $494-675$ & $\ldots$ \\
\hline
\end{tabular}

a Taken from reference 15

b Estimates made from reference 12.

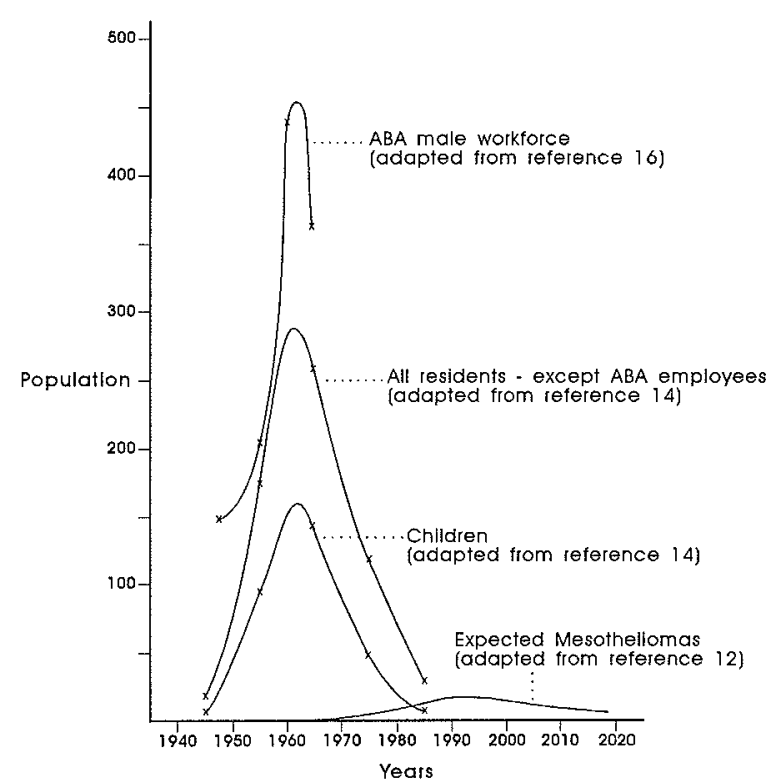

Figure 1. Population distribution - Australian blue asbestos (ABA) employees, town residents, and mesothelioma cases.

from washing spouses' clothing and playing in tailings, or child susceptibility, may distort the differences.

So that the importance of the difference in the residence duration and degree of exposure between the mine working population and that of the township could be examined, incidence rates in terms of person-years were calculated using the duration data of Armstrong et al (16) and Hansen et al (14). The comparative mesothelioma rates were as follows: 67.9 (95\% CI 57.7-79.8) per person 1000 years for employees at the mine site; 5.9 (95\% CI 2.5-12.3) per person 1000 years for residential adult females; 3.2 (95\% CI 1.8-5.5) per person 1000 years for residential children.

\section{Discussion}

Occupationally and environmentally induced lung cancer and mesothelioma will continue to be observed in the future partly as a result of latency effects from past exposures during the operation of the mine, partly from contamination of the township by the continued use of tailings up until the late 1970s, and partly due to future contact with the residual contamination of the township and mine site. The relative effects are explored in the following discussion.

Cases due to latency effects from the active mining phase (1940s-1966).

The predicted number of cases of mesothelioma due to latency effects ( $20-45$ years) from the mining operation 
phase have been listed in table 2 and figure 1 . Some 384 future mesothelioma cases are expected by the year 2020 . With this calculation a simplified view was taken that the proportion of men employed in each occupation was constant and that exposures during the entire operation of the mine and mill were also constant. For the period $1991-1995$ the number predicted is 15.6 per year (12), which is remarkably close to the value observed $(\mathrm{N}=16)$ by 1994 . There has been an increase in the proportion of environmental cases from $15 \%$ in $1979-1992$ to $37 \%$ in 1992 - 1994. In addition the 1992-1994 cases indicate a higher proportion of female town residents than predicted. This difference may be due to a random cluster of events or may be a consequence of the previously observed low numbers of environmental cases used in the original predictive calculations. For the combined data sets the environmental cases observed from 1979 through 1994 compare favorably with case records collected separately over a different period (14).

Wittenoom appears to have produced a smaller proportion of environmental mesotheliomas than has been reported from the crocidolite mining areas in South Afri$\mathrm{ca}$. Both the initial report from Wagner (17) and a later report on a series of 70 mesotheliomas from the same region (18) indicated that approximately $50 \%$ of the cases were associated with residential exposure in the mining towns rather than from direct occupational employment in the mines or mills.

\section{Cases due to environmental exposure in 1966-1992}

Although mining activity had ceased in 1966, it took a number of decades for the town population to decline to the present levels (figure 1). Due to the relatively short time since exposure, it is not possible using proportional latency calculations to estimate future cases of mesothe- lioma. However the cumulative town population during this period was around $40 \%$ of the total $(\sim 2000)$, the use of tailings ceased, and there was a considerable program of tailing clean-up in the town areas. A review of both personal and stationary monitoring surveys indicates that airborne exposures in and around the town had declined to less than $1 \%$ of the values obtained in the early 1970 s (0.2 fibers per cubic centimeter $\left(\mathrm{f} \cdot \mathrm{cc}^{-1}\right)$ in $1973,0.03 \mathrm{f}$. $\mathrm{cc}^{-1}$ in $1978,<0.015 \mathrm{f} \cdot \mathrm{cc}^{-1}$ in $1980,<0.002 \mathrm{f} \cdot \mathrm{cc}^{-1}$ in $1985,<0.001 \mathrm{f} \cdot \mathrm{cc}^{-1}$ in $1990,<0.002 \mathrm{f} \cdot \mathrm{cc}^{-1}$ in 1992) (8). Assuming linearity, it could be expected that less than one environmental case of mesothelioma [(112 from table 2) $\times 0.4 \times 0.01$ ] would occur from the town population in 1967-1992. This is equivalent to 20 cases per million of the population for the 25 -year contact period.

\section{Cases due to environmental exposure after 1992}

Because of the continuation of tailing clean-up in the township, it could be expected that the risk to the 45 residents would be less than for the period 1966-1992. Some $35000-40000$ tourists visit the Wittenoom Gorge and surrounding national park annually. Table 3 provides a range of risk estimates based on airborne exposure levels measured in 1992 using different risk models $(5,19)$.

In comparison a lifetime rate as high as 260 mesotheliomas per million persons ( 4.4 per million per year) is observed for the Australian population on the basis of calculations made using cases with no significant occupational or environmental exposure to asbestos (11).

A comparison of nonasbestos risks was also made for tourists visiting the area. According to government records of an annual average of 35000 tourist visitors, four recorded deaths due to falls in the Gorge since the opening of the national park in 1969 (1976, 1986, 1987,

Table 3. Risk estimates for exposure at Wittenom, post-1992. ${ }^{a}$

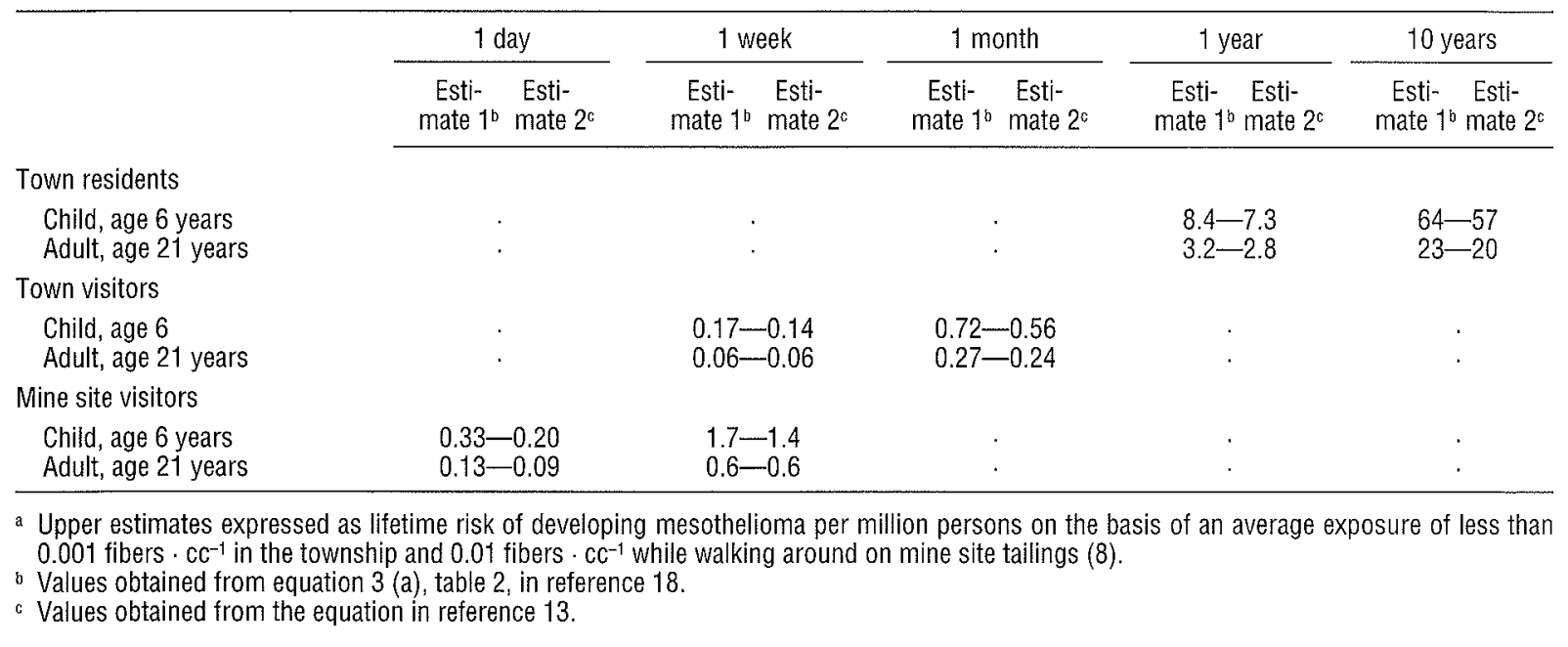


1990) and two fatalities and fourteen serious injuries on the roads surrounding the national park during June 1985-March 1992, the risk was 3.2 deaths from falls per million visitors and 0.5 deaths as well as 3.4 serious injuries due to motor vehicle accidents per million visitors.

In summary the numeric risks can be placed in a hierarchy of relative risk compared with the nonasbestos mesothelioma rate determined for the Australian population. The relative risk of mesothelioma or other causes was as follows: 1.0 for the normal unexposed Australian population, 1.0004 for a one-week visit to Wittenoom town after 1992, 1.002 for tourist road deaths in the Wittenoom area, 1.003 for a one-week visit to the Wittenoom mine site after 1992, 1.012 tourist deaths from gorge falls in the national park, 1.013 serious injuries to tourists from motor vehicle accidents, 1.08 for adult 10 year residents in Wittenoom after 1992, 1.23 for child 10-year residents in Wittenoom after 1992, 41 for child residents in Wittenoom before 1970, 74 for adult female residents in Wittenoom before 1970 , and 232 for miners and millers employed in Wittenoom before 1966.

The historical mining of crocidolite and the use of tailings in the township of Wittenoom have created a considerable legacy of mesothelioma which will be subject to considerable public concern. While approximately $40 \%$ of the occupational and environmental cases have been expressed, many more will occur over the next 20 years with a slow decline in numbers predicted until approximately 2010. While even though past exposures have produced this legacy, calculations indicate that the risk of developing mesothelioma from current environmental exposures is around the same order as other nonasbestos risks found in the area.

\section{Acknowledgments}

We thank Dr de Klerk, University of Western Australia, and Professor Berry, University of Sydney, for providing risk calculations, and Dr Musk and his co-researchers at the Sir Charles Gardiner Hospital for their collaboration in providing population estimates. We are grateful to the current residents of Wittenoom for their assistance in dealing with what must be for them a difficult subject.

Disclaimer: The data presented in this paper are the result of research conducted by the authors and do not necessarily reflect the views of the authors' organizations.

\section{References}

1. Broadhurst $\mathrm{CH}$. Blue asbestos industry in Western Australia. Chem Eng Mining Review 1956;15:37-40.

2. McNulty JC. Malignant pleural mesothelioma in an asbestos worker. Med J Aust 1962;24 II:953-4.

3. de Klerk N, Musk A, Armstrong B, Hobbs M. Diseases in miners and millers of crocidolite from Wittenoom, Western Australia: a further follow-up to December 1986. In: Dodson J, McCallum R, editors. Inhaled particles VII: proceedings of an international symposium organised by the British Occupational Hygiene Society Edinburgh, September 1991. Oxford: Pergamon Press, 1994:647-55.

4. de Klerk N, Armstrong B, Musk A, Hobbs M. Predictions of future cases of asbestos related disease among former miners and millers of crocidolite in Western Australia. Med J Aust $1989 ; 151: 616-20$.

5. Jones H. Visit to the Colonial Mine Wittenoom. Perth: Western Australia Department of Mines, 1990.

6. Cumpston AG. The health hazard at Wittenoom. Perth: Public Health Department of Western Australia, 1978.

7. Cumpston AG. Exposure to crocidolite at Wittenoom. Perth: Public Health Department of Western Australia, 1979.

8. Arden H. Journey into dreamtime. Natl Geogr 1991;179:8 40.

9. Nevill M, Rogers A. Inquiry into asbestos issues at Wittenoom. Perth: Legislative Council of Western Australia, 1992.

10. Ferguson D, Berry G, Constance T, Jelihovsky T, Andreas S, Rogers A, et al. Report of the Australian mesothelioma surveillance program 1979-1985. Med J Aust 1987;147:166 — 71 .

11. Leigh J, Corvalan C, Grimwood A, Berry G, Ferguson D, Thompson $\mathrm{R}$. The incidence of malignant mesothelioma in Australia 1982 - 1988. Am J Ind Med 1991;20:643-55.

12. Rogers A. Predictions of mesothelioma in former Wittenoom asbestos workers. Br J Ind Med 1992;49:451-2.

13. Dobson AJ, Kuulasmaa K, Eberle E, Scherer J. Confidence intervals for weighted sums of Poisson parameters. Stat Med 1991;10:457-62.

14. Hansen J, de Klerk N, Eccles J, Musk AW, Hobbs M. Malignant mesothelioma after environmental exposure to blue asbestos. Int J Cancer 1993;54:578—81.

15. Berry G. Predictions of mesothelioma, lung cancer and asbestosis in former Wittenoom asbestos workers. $\mathrm{Br} \mathrm{J}$ Ind Med 1991;48:793-802.

16. Armstrong B, de Klerk N, Musk B, Hobbs M. Mortality in miners and millers of crocidolite in Western Australia. $\mathrm{Br} J$ Ind Med 1988:45:5 - 13

17. Wagner J, Sleggs C, Marchand P. Diffuse pleural mesothelioma and asbestos exposure in the Northwestern Cape Province. Br J Ind Med 1960;17:260-71.

18. Cochrane J, Webster I. Mesothelioma in relation to asbestos fibre exposure, S A Med J 1978;54:279-81.

19. Berry G. Environmental mesothelioma incidence, time since exposure to asbestos and level of exposure. Environmetrics. In press.

Received for publication: 22 August 1994 